\title{
Catalyst Nucleation and Carbon Nanotube Growth from \\ Flame-Synthesized Co-Al-O Nanopowders at Ten-Second Time Scale
}

Hiroyuki Shirae ${ }^{\mathrm{a}}$, Kei Hasegawa ${ }^{\mathrm{a}}$, Hisashi Sugime ${ }^{\mathrm{b}}$, Eongyu $\mathrm{Yi}^{\mathrm{c}}$, Richard M. Laine ${ }^{\mathrm{c}}$, Suguru Noda $^{a, *}$

${ }^{a}$ Department of Applied Chemistry, School of Advanced Science and Engineering, Waseda University, 3-4-1 Okubo, Shinjuku-ku, Tokyo 169-8555, Japan

${ }^{b}$ Waseda Institute for Advanced Study, Waseda University, 1-6-1 Nishiwaseda, Shijuku-ku, Tokyo 169-8050, Japan

${ }^{c}$ Department of Materials Science and Engineering and the Macromolecular Science and Engineering Center, University of Michigan, Ann Arbor, Michigan 48109-2136, USA

Abstract: Flame-synthesized $(\mathrm{CoO})_{x}\left(\mathrm{Al}_{2} \mathrm{O}_{3}\right)_{1-x}$ spinel nanopowders with primary particles of $\sim 20 \mathrm{~nm}$ were used to grow small diameter carbon nanotubes (CNTs). The nanopowder with $x$ $\leq 0.35$ grew few CNTs whereas that with $x=0.65$ grew CNTs efficiently. Low crystalline and large-diameter multi-wall CNTs grew by annealing and chemical vapor deposition (CVD) at $800{ }^{\circ} \mathrm{C}$ for $\sim 10 \mathrm{~min}$, whereas single-wall CNTs with high crystallinity (G-band to D-band intensity ratio of $20-100$ by Raman spectroscopy) grew by annealing and CVD at $\geq 1000{ }^{\circ} \mathrm{C}$ for $\sim 10$ s. The excess Co in the spinel reduced and segregated to form multiple Co nanoparticles on the surface of the single primary alumina nanoparticles in $\sim 10 \mathrm{~s}$, yielding SWCNTs in $\sim 10$ s. Such flame synthesized nanopowders, reduced and activated by $\mathrm{H}_{2}$, provide CNTs from $\mathrm{C}_{2} \mathrm{H}_{2}$, all in ten-second time scale, and as such are promising for practical, high-through-put production of small-diameter CNTs.

\footnotetext{
${ }^{*}$ Corresponding author. E-mail address: noda@waseda.jp (Suguru Noda).
} 


\section{Introduction}

Carbon nanotubes (CNTs) are attractive one-dimensional carbon nanomaterials offering diverse properties including excellent electrical and thermal conductivities, carrier mobility, chemical and thermal stability, light-weight, mechanical flexibility and compatibility with solution processing. Utility in various applications are anticipated including transparent electrodes [1,2], flexible transistors [3], integrated circuits [4,5], electrochemical capacitors [6,7] and rechargeable batteries [8,9]. Many prototype devices have demonstrated excellent performance, however, efforts are still needed to establish methods of low cost production of highly crystalline CNTs to realize their practical and wide use in society.

Chemical vapor deposition (CVD) has been studied extensively for practical production of CNTs, in which carbon source gases are catalytically decomposed typically around $600-1200{ }^{\circ} \mathrm{C}$. Metal nanoparticles are crucially important as templates controlling CNT diameter and as catalysts promoting CNT formation vs non-catalytic soot formation. There are two ways to employ catalysts, one is by suspending the catalyst in the gas flow [1013] and the other is by supporting catalysts on flat substrates [14-17] or ceramic powders [18-21]. The former catalyst is used typically for $\leq 10 \mathrm{~s}$ due to the limited residence time of the gas flow whereas the latter catalyst is used typically for 10 min-a few hours until deactivated by carbonization [22,23], oxidation [24], and/or coarsening [22,25]. Catalysts are used for much shorter times in CNT syntheses than in conventional chemical processes such as petrochemistry (typically several months), and therefore it is crucially important to prepare good catalysts quickly via practical processes.

In this paper, we demonstrate rapid CVD growth of CNTs in ten-second time scale using flame synthesized $(\mathrm{CoO})_{x}\left(\mathrm{Al}_{2} \mathrm{O}_{3}\right)_{1-x}$ nanopowders as supported catalysts. Fe [16,17,24] and Co [26] nanoparticles supported on $\mathrm{AlO}_{x}$ are excellent catalysts growing single- and few-wall CNTs (SWCNTs and FWCNTs) at a few $\mu \mathrm{m} / \mathrm{s}$. And we have developed liquid-feed 
flame spray pyrolysis (LF-FSP) which provides single phase but mixed-metal oxides with primary diameter of 10-30 nm over a wide composition range for various metal oxides including the Co-Al-O system [27]. Metalloorganic precursors of $\mathrm{Co}$ and $\mathrm{Al}$ are dissolved in organic solvent, aerosolized with $\mathrm{O}_{2}$, and combusted to produce off-stoichiometric $(\mathrm{CoO})_{x}\left(\mathrm{Al}_{2} \mathrm{O}_{3}\right)_{1-x}$ nanopowders with different ratios of $x$ by controlling the ratio of the metalloorganic precursors. We have targeted forming $\mathrm{Co} / \mathrm{Al}_{2} \mathrm{O}_{3}$ catalysts via in situ reduction of the metastable nanopowders.

Our ultimate goal is to suspend the nanopowders in the gas flow and feed the gas to the reactor continuously to mass-produce CNTs. But it is not easy to study the reaction processes of gas-suspended nanopowders. In this work, as the first step, we studied such reactions at ten-second time scale fundamentally by fixing the nanopowders on $\mathrm{Si}$ substrates; the nanopowders are exposed to our previously developed electrical current heating method of Si substrates which enables quick heating and cooling in one-second time scale $[28,29]$. Such short annealing times likely suppresses coarsening of catalyst nanoparticles [22,25], a common problem for CNT production. In addition, the amount of CNTs per catalyst support can be increased because the nanopowders have the high specific surface area of $20-60 \mathrm{~m}^{2} / \mathrm{g}$ [27]. Such nanopowders would be promising as inexpensive supported catalysts for practical CNT production.

\section{Experimental}

2.1. Catalyst nanopowders used as supported catalysts for CNTs

$(\mathrm{CoO})_{x}\left(\mathrm{Al}_{2} \mathrm{O}_{3}\right)_{1-x}$ nanopowders with different compositions were used as supported catalysts. The elemental compositions of the nanopowders were analyzed by scanning electron microscopy (SEM; Hitachi S-4800, Tokyo, Japan) equipped with energy-dispersive X-ray spectroscopy (EDS; EDAX Genesis, AMETEK, Elancourt, France). The nanopowders were 
also analyzed by inductively coupled plasma (ICP)-optical emission spectroscopy (OES) (Agilent Technologies ICP-OES 5100, Hachioji, Japan) following the method explained in Supplementary data. The results are summarized in Table 1, which shows good agreement between the two methods. Hereafter, the nanopowders are named with the $x$ value calculated from the composition by SEM-EDS using the equation: $x=\mathrm{Co} /(\mathrm{Co}+0.5 \mathrm{Al})$.

The as-synthesized nanopowders with $x=0.05,0.08,0.35$ show blue color while that with $x=0.65$ shows black color (Fig. 1a). From the phase diagram for the $\mathrm{CoO}$ and $\mathrm{Al}_{2} \mathrm{O}_{3}$ system [27], the stoichiometric source with $x=0.50$ should yield $\mathrm{CoAl}_{2} \mathrm{O}_{4}$ spinel at the temperature of the LF-FSP method. Al-rich source with $x<0.50$ should yield spinel unsaturated with $\mathrm{CoO}$, some of which may phase-separate into spinel and $\mathrm{Al}_{2} \mathrm{O}_{3}$. Whereas Co-rich source with $x>0.50$ should yield spinel oversaturated with $\mathrm{CoO}$, some of which may phase-separate into spinel and $\mathrm{CoO}$. Because the spinel, $\mathrm{Al}_{2} \mathrm{O}_{3}$, and $\mathrm{CoO}$ show respective colors of blue, white, and black, the Al-rich sources with $x=0.05,0.08$, and 0.35 should have yielded nanopowders composed of the spinel and $\mathrm{Al}_{2} \mathrm{O}_{3}$ while the Co-rich source with $x=$ 0.65 should have yielded nanopowder containing $\mathrm{CoO}$. Actually, $\mathrm{CoO}$ was detected by X-ray diffraction (XRD; SmartLab, Akishima, Japan) in addition to the spinel for the nanopowder with $x=0.65$ (Supplementary data, Fig. S1).

Table 1 - Elemental composition of the as-synthesized nanopowders. Each nanopowder was analyzed at 8-14 points by SEM-EDS. Average and standard deviation values are shown in at \%.

\begin{tabular}{lllll} 
Sample & Co & $\mathrm{Al}$ & $\mathrm{O}$ & $x$ by ICP-OES \\
\hline$x=0.05$ & $1.2 \pm 1.1$ & $46.7 \pm 8.4$ & $52.1 \pm 8.8$ & 0.041 \\
$x=0.08$ & $2.2 \pm 0.9$ & $48.9 \pm 7.3$ & $49.0 \pm 8.2$ & 0.089 \\
$x=0.35$ & $11.4 \pm 2.2$ & $42.0 \pm 4.2$ & $46.6 \pm 4.8$ & 0.34 \\
$x=0.65$ & $27.2 \pm 18.4$ & $29.6 \pm 4.5$ & $43.2 \pm 15.3$ & 0.62 \\
$x=0.41$ & $12.9 \pm 5.0$ & $36.7 \pm 4.2$ & $50.3 \pm 6.8$ & - \\
\hline
\end{tabular}

2.2. Catalyst activation and CNT growth by electrical current heating at ten-second time scale 
Each nanopowder $(1 \mathrm{mg})$ was dispersed in $\mathrm{C}_{2} \mathrm{H}_{5} \mathrm{OH}(1 \mathrm{~mL})$ for 1 min by using an ultrasonic bath (VS-F100, AS ONE, Osaka, Japan) (Fig. 1b). A $\mathrm{SiO}_{2}(50 \mathrm{~nm}) / \mathrm{Si}$ substrate (phosphor-doped, $1.2 \mathrm{~m} \Omega \mathrm{cm}, 15 \times 15 \mathrm{~mm}^{2}$ ) was pretreated with a mixture of sulfuric acid and hydrogen peroxide (3:1 v/v) to remove contaminations and make the substrate surface hydrophilic, on which the dispersion (10 $\mu \mathrm{L}$ ) was spin-coated (4000 rpm, for $20 \mathrm{~s}$ ) (Fig 1c). The substrate was cut into three pieces of $5 \times 15 \mathrm{~mm}^{2}$ and fixed to the metal electrodes with screws in a quartz glass tube (inner diameter of $21 \mathrm{~mm}$ ) (Fig. 1d). The substrate was annealed at $900-1230{ }^{\circ} \mathrm{C}$ for $10 \mathrm{~s}$ under ambient pressure by Joule heating of the Si substrate using a DC power supply $[28,29]$. The gas composition during the annealing was $\mathrm{H}_{2}(12.5 \mathrm{vol} \%) / \mathrm{CO}_{2}$ (3.8 vol\%)/Ar (83.7 vol\%) and the total flow rate was $300 \mathrm{sccm}$. Then, CNTs were grown for $10 \mathrm{~s}$ by adding $\mathrm{C}_{2} \mathrm{H}_{2} / \mathrm{Ar}$ while keeping the temperature and the flow rate of other gases (Fig. 1e). The gas during the growth was $\mathrm{C}_{2} \mathrm{H}_{2}(0.5 \mathrm{vol} \%) / \mathrm{H}_{2}(10 \mathrm{vol} \%) / \mathrm{CO}_{2}(3.0 \mathrm{vol} \%) / \mathrm{Ar}(86.5$ vol\%) and $375 \mathrm{sccm}$. The temperature profile measured by a radiation thermometer (Chino IR-CQI 20C, Itabashi-ku, Japan) showed that the temperature for annealing and growth was controllable at the one-second time scale.

\subsection{CNT growth by conventional thermal CVD}

CNTs were also grown by conventional thermal annealing and growth, each for $10 \mathrm{~min}$ in a horizontal quartz glass tube (inner diameter $34 \mathrm{~mm}$ and hot zone length of $300 \mathrm{~mm}$ ) [22,24]. The nanopowder with $x=0.65$ was spin coated on an Si substrate. The nanopowder was annealed at 800 or $900{ }^{\circ} \mathrm{C}$ for $10 \mathrm{~min}$ in $\mathrm{H}_{2}(11 \mathrm{vol} \%) / \mathrm{CO}_{2}$ (3.4 vol\%)/Ar (85.6 vol\%) with a total flow rate of $440 \mathrm{sccm}$, then CNTs were grown for 10 min by adding $\mathrm{C}_{2} \mathrm{H}_{2} / \mathrm{Ar}$ while keeping the temperature and the flow rate of other gases. The gas composition during growth was $\mathrm{C}_{2} \mathrm{H}_{2}(0.3 \mathrm{vol} \%) / \mathrm{H}_{2}(10 \mathrm{vol} \%) / \mathrm{CO}_{2}(3.0 \mathrm{vol} \%) / \mathrm{Ar}(86.7 \mathrm{vol} \%)$ at $500 \mathrm{sccm}$. 


\subsection{Characterization of nanopowders and CNTs}

As-grown CNTs were characterized by SEM-EDS. The crystallinity was estimated by calculating the intensity ratio of the $\mathrm{G}$ band $\left(\sim 1590 \mathrm{~cm}^{-1}\right)$ to the $\mathrm{D}$ band $\left(\sim 1350 \mathrm{~cm}^{-1}\right)$ by micro-Raman scattering spectroscopy (HR-800, Horiba, Kyoto, Japan) excited with an $\mathrm{Ar}^{+}$ laser (488 nm). Also, typical as-grown CNTs were shaved off together with $\mathrm{SiO}_{2}$ using a diamond pen and characterized by transmission electron microscope (TEM; JEOL JEM-2100F, Akishima, Japan).

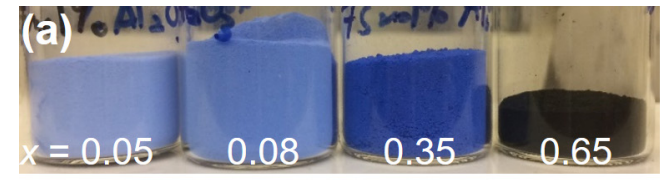

(b)
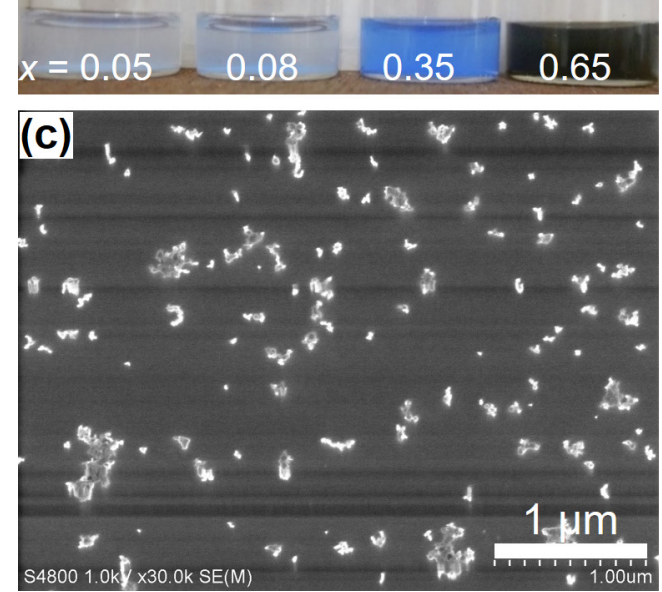

(d)
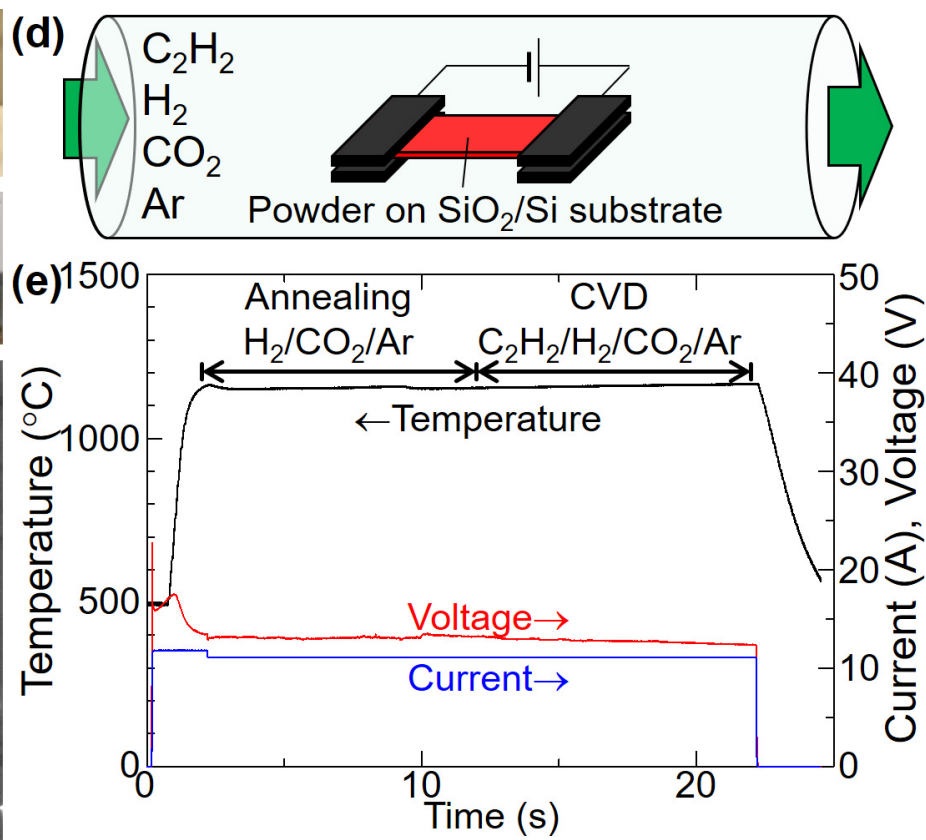

Fig. 1 - Materials and apparatus for CNT growth experiment. (a) Optical image (OM) of the $(\mathrm{CoO})_{x}\left(\mathrm{Al}_{2} \mathrm{O}_{3}\right)_{1-x}$ nanopowders. (b) $\mathrm{OM}$ of $1 \mathrm{mg}$ of the nanopowders dispersed for $1 \mathrm{~min}$ in 1 mL $\mathrm{C}_{2} \mathrm{H}_{5} \mathrm{OH}$. (c) SEM of nanopowder $(x=0.65)$ spin-coated on $\mathrm{SiO}_{2} / \mathrm{Si}$ substrate. (d) Schematic illustration of the apparatus for electrical current heating CVD. (e) Typical time profile of the substrate temperature during electrical current heating CVD.

\section{Results and discussion}

3.1. CNT growth from nanopowders at ten-second time scale by electrical current heating CVD 
Fig. 2 shows SEMs and Raman spectra of the CNTs grown from the nanopowders with $x=$ 0.05-0.65 under the standard condition of electrical current heating CVD. Most nanopowders with $x=0.05,0.08,0.35$ (the dark sub- $\mu$ m-sized dots) did not grow CNTs (Fig. 2a-c), whereas CNTs grew well from the nanopowder with $x=0.65$ (Fig. 2d). The existence of excess Co in the nanopowder with $x=0.65$ should be responsible for its high catalytic activity for the CNT growth.
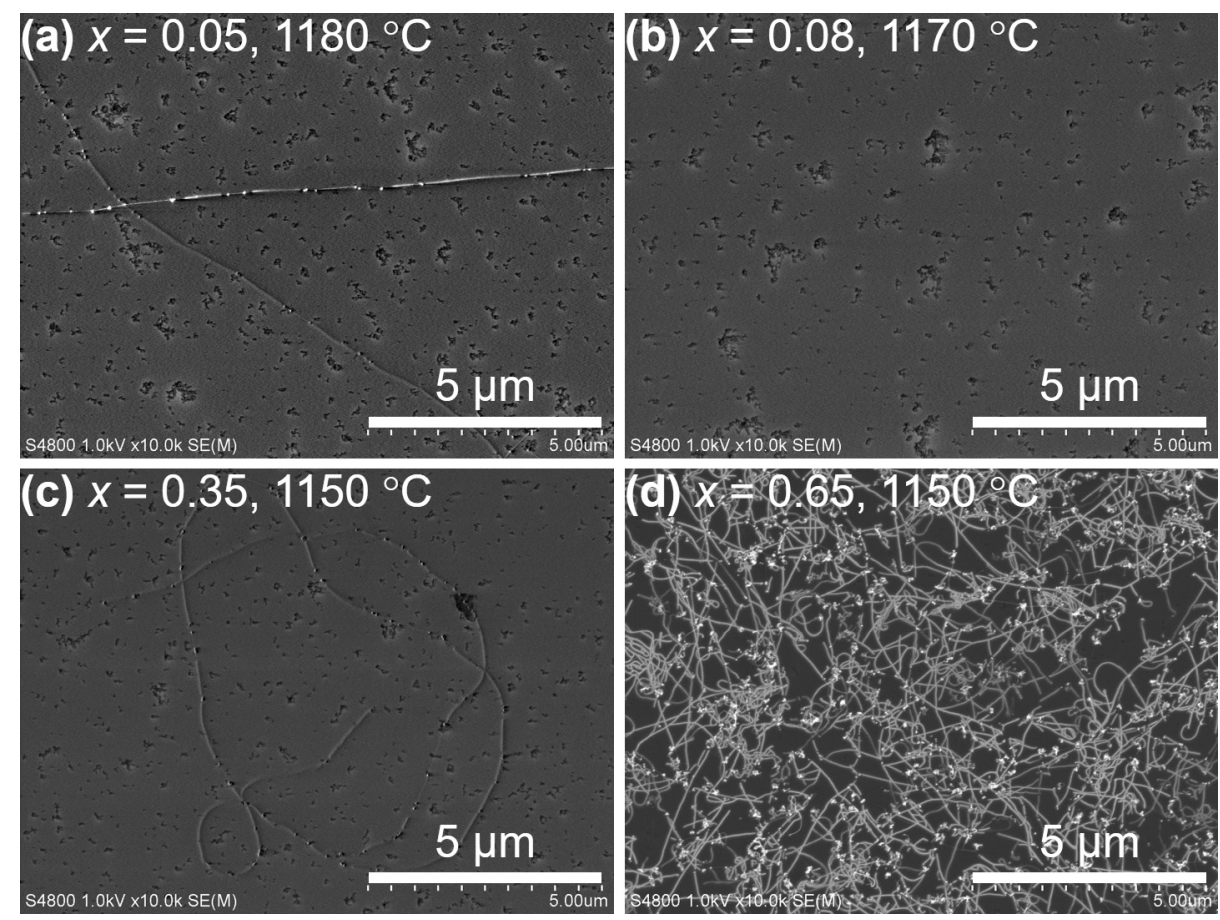

Fig. 2 - SEMs of as-grown CNTs from the nanopowders by annealing for $10 \mathrm{~s}$ with $\mathrm{H}_{2}(10$ vol\%)/CO $/ \mathrm{CO}_{2}$ (3 vol\%)/Ar and CVD for $10 \mathrm{~s}$ with $\mathrm{C}_{2} \mathrm{H}_{2}(0.5 \mathrm{vol} \%) / \mathrm{H}_{2}(10 \mathrm{vol} \%) / \mathrm{CO}_{2}$ (3 vol\%)/Ar. Powder composition and temperature are indicated on the images. The nanopowders with $x=$ (a) 0.05 , (b) 0.08 , (c) 0.35 were inert whereas that with $x=$ (d) 0.65 was active for CNT growth.

Fig. 3 shows typical TEMs of as-synthesized nanopowder with $x=0.65$ (without annealing and growth). The bright-field image and the histogram (Fig. 3a,b) show $\mu \mathrm{m}$ size secondary particles composed of gray-colored primary particles $20 \pm 8 \mathrm{~nm}$. Some black 
particles can also be observed on some primary particles, showing uneven distribution and some segregation of $\mathrm{CoO}$. We note that the bright field image shows the heavy element (Co) as a dark contrast. On the other hand, the dark field image and the elemental mapping results show quite similar patterns, showing that $\mathrm{Co}$, $\mathrm{O}$, and $\mathrm{Al}$ typically co-exist uniformly in the nanopowder (Fig. 3d-f). When we carefully compare the elemental mapping results of Co and $\mathrm{Al}$, we can find some regions with high Co contents and low $\mathrm{Al}$ contents (indicated by white circles in Fig. 3e,f). Such regions possibly correspond to the segregated $\mathrm{CoO}$ nanoparticles found in the bright-field image (Fig. 3a) and XRD spectrum (Fig. S1). Other nanopowders were also analyzed by SEM-EDS and ICP-OES. The compositions of all samples are summarized in Table 1. Co content in the stoichiometric $\mathrm{CoAl}_{2} \mathrm{O}_{4}$ spinel is 14.3 at\%, and only the nanopowder with $x=0.65$ had excessive Co. Such excessive Co possibly segregates and forms Co nanoparticles on the spinel primary particles on annealing and catalyzes CNT growth during CVD. Co contained in the spinel primary particles at Co $<14.3$ at\% possibly does not segregate to the surface on annealing for $\sim 10 \mathrm{~s}$ and yielded few CNTs during CVD. 

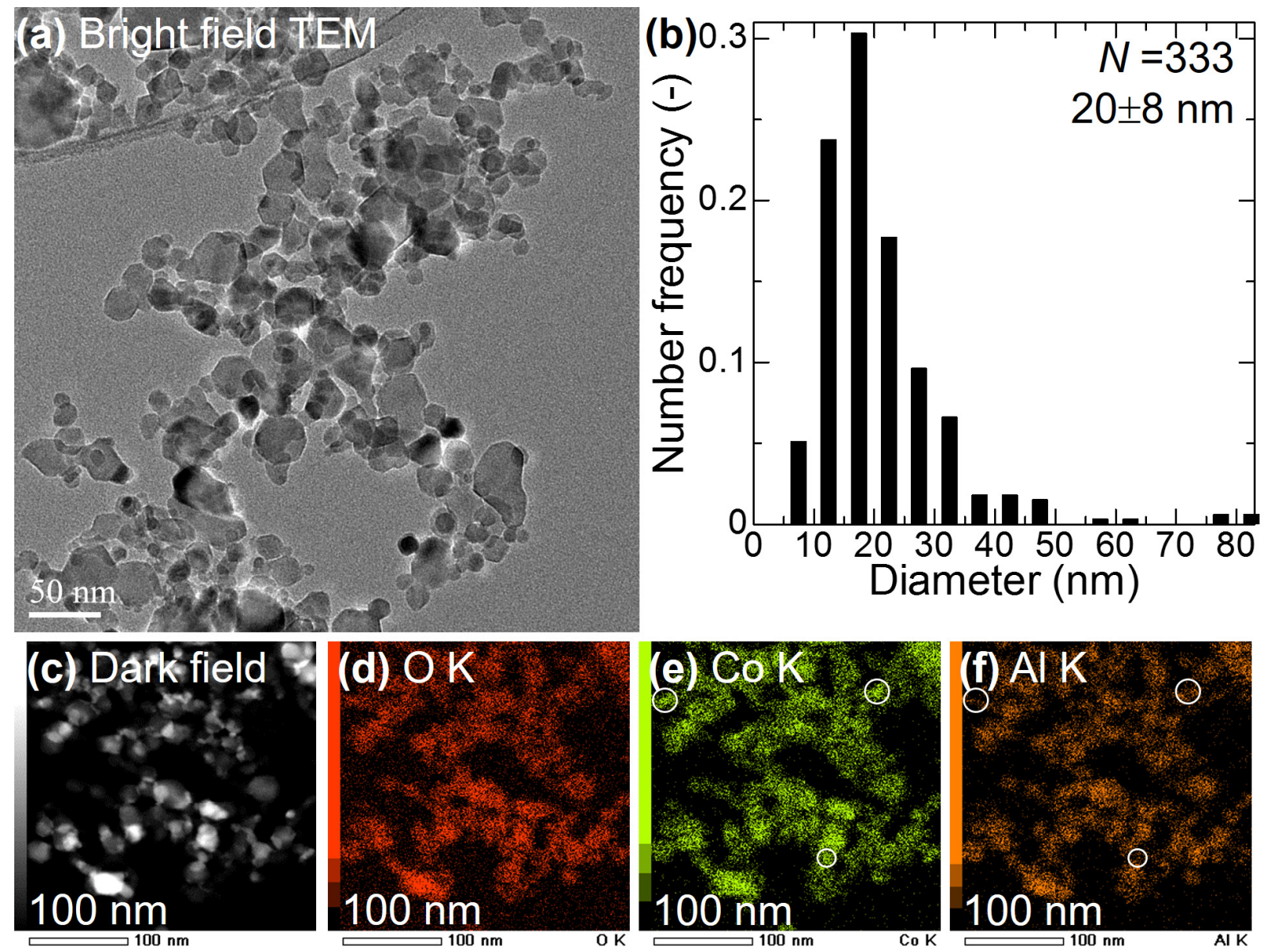

Fig. 3 - TEM analysis of the as-synthesized nanopowder with $x=0.65$ (before annealing/CVD). (a) Bright field TEM image. (b) The diameter distribution with average diameter and standard deviation of the primary particles. (c) Dark-field image and $(\mathrm{d}-\mathrm{f})$ TEM-EDS element mappings. White circles in (e) and (f) show the regions with high Co contents and low $\mathrm{Al}$ contents.

Next, as-grown CNTs on the nanopowder with $x=0.65$ were observed by TEM (Fig. 4). The images show formation of SWCNTs (Fig. 4a-c), FWCNTs with diameters of 5-10 nm (Fig. 4d), and multi-wall CNTs (MWCNTs) with diameters $>10 \mathrm{~nm}$ (Fig. 4e). The CoO particles on the primary particles in the as-synthesized nanopowder (Fig. 3a) had diameters $\geq 10 \mathrm{~nm}$, likely responsible for the MWCNT growth. We also observed multiple Co nanoparticles on a single primary nanoparticle (Fig. 4f). Excess Co contained in the 
as-synthesized nanopowder (Fig. 3e,f) possibly segregated and reduced to form multiple Co nanoparticles without aggregation in $10 \mathrm{~s}$ (Fig. 4d) promoting growth of SWCNTs in successive 10-s CVD (Fig. 4a-c). Actually, we observed that nanoparticles (possibly CoO) segregated to the surface of the primary particles by the annealing for $10 \mathrm{~s}$ under pure $\mathrm{Ar}$ without reduction at $1000{ }^{\circ} \mathrm{C}$ (Supplementary Information, Fig. S2). Thus it is probable that the Co first segregated as $\mathrm{CoO}$ on primary particles and then was reduced with $\mathrm{H}_{2}$ to form $\mathrm{Co}$ nanoparticles.
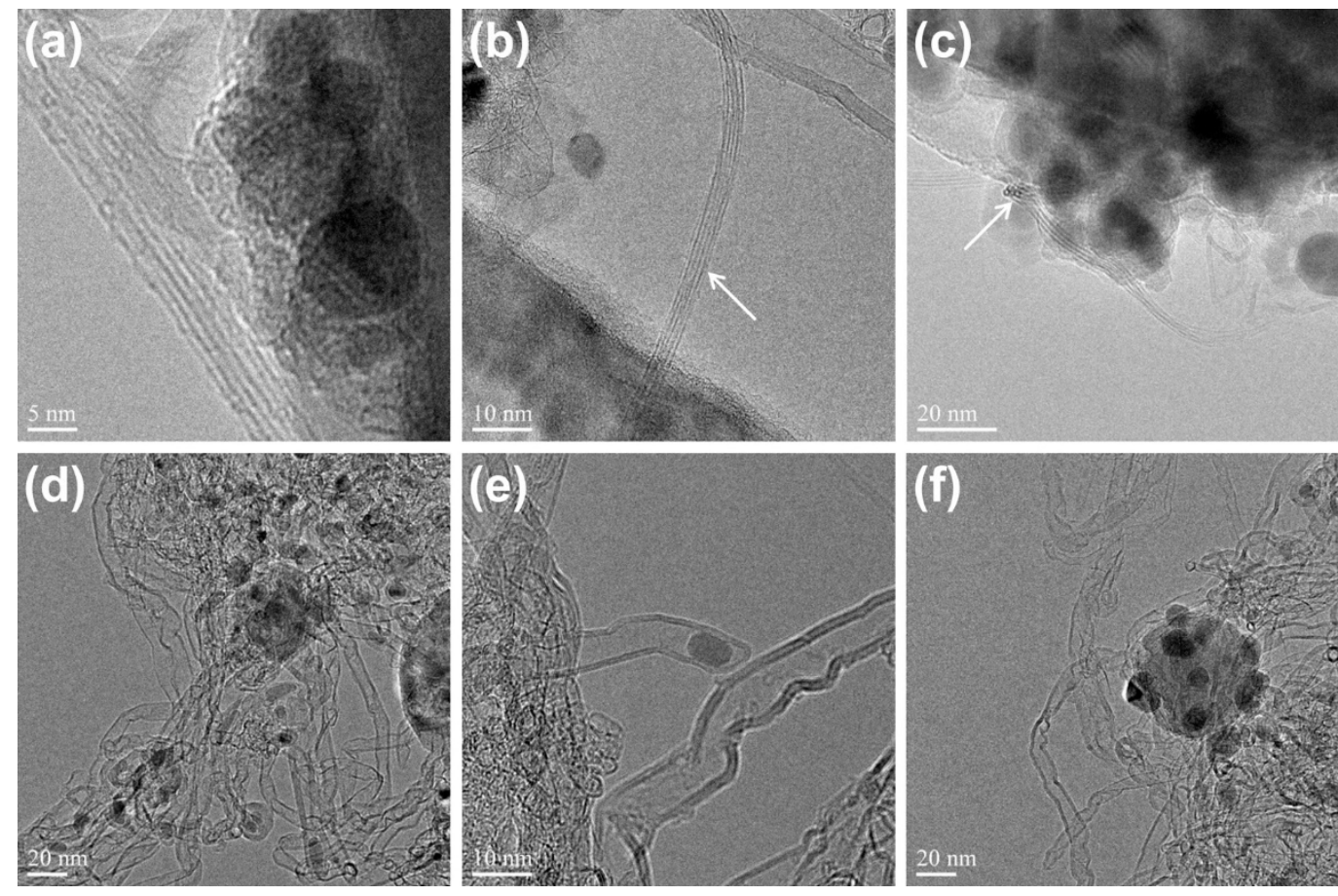

Fig. 4 - TEMs of CNTs grown from the nanopowder with $x=0.65$ at ten-second time scale by current-heating CVD method (annealing for $10 \mathrm{~s}$ with $\mathrm{H}_{2}(10 \mathrm{vol} \%) / \mathrm{CO}_{2}$ (3 vol\%)/Ar, CVD for 10 s with $\mathrm{C}_{2} \mathrm{H}_{2}\left(0.5\right.$ vol\%)/ $\mathrm{H}_{2}\left(10\right.$ vol\%)/CO $\mathrm{CO}_{2}$ (3 vol\%)/Ar at $\left.1170{ }^{\circ} \mathrm{C}\right)$. (a-c) SWCNTs, (d) FWCNTs, (e) MWCNTs, and (f) multiple Co nanoparticles on a single primary nanoparticle. White arrows in (b,c) show SWCNTs.

\subsection{CNT growth from nanopowder at ten-minute time scale by conventional thermal CVD}

Above we find that the nanopowder with $x=0.65$ exhibit high catalytic activity for the 
SWCNT growth with 10-s annealing and 10-s CVD by the electrical current heating method. We compare these results with conventional thermal CVD which generally takes tens of minutes. Fig. 5 shows SEMs and Raman spectra of as-grown CNTs produced by thermal annealing for $10 \mathrm{~min}$ followed by growth for $10 \mathrm{~min}$. This conventional thermal CVD produces either wavy short CNTs or large-diameter, long CNTs at $800{ }^{\circ} \mathrm{C}$ (Fig. 5a), which show Raman spectra with large D- and broad G-band peaks without any radial breathing mode (RBM) peak, showing MWCNTs of low crystallinity (Fig. 5c). Whereas it produces longer and straighter CNTs at $900{ }^{\circ} \mathrm{C}$ (Fig. 5b), which showed Raman spectra with small Dand sharp G-band peaks with some RBM peaks (Fig. 5c). The TEM shows many MWCNTs with a few SWCNTs (Fig. 5d). These results show that the $(\mathrm{CoO})_{x}\left(\mathrm{Al}_{2} \mathrm{O}_{3}\right)_{1-x}$ nanopowder with $x=0.65$ can yield CNTs including some SWCNTs (by conventional CVD) in 10 min at 900 ${ }^{\circ} \mathrm{C}$, and CNTs with SWCNTs (by pulse-current heating CVD) in much shorter time of $10 \mathrm{~s}$ at $1000{ }^{\circ} \mathrm{C}$ or above. 

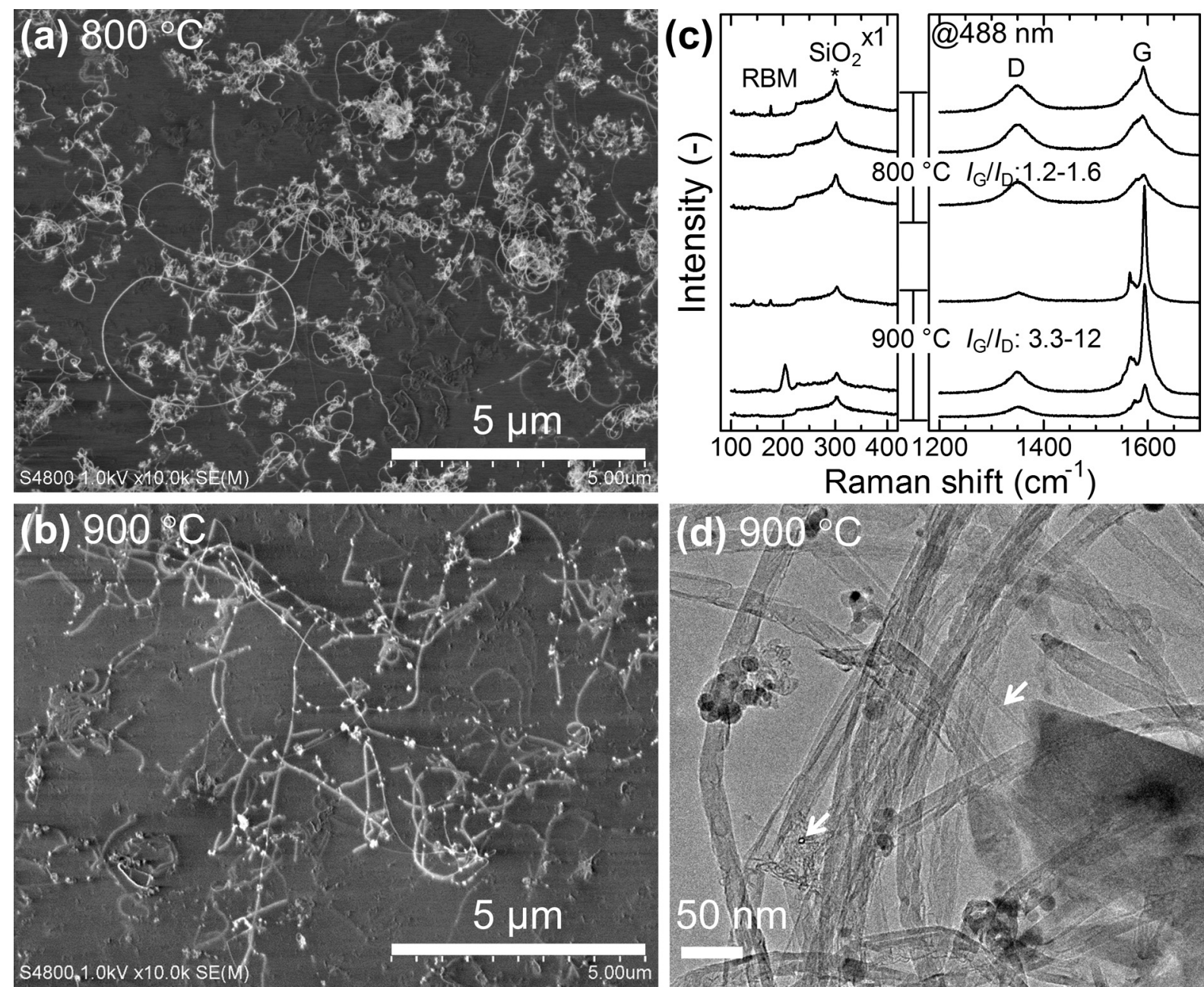

Fig. 5 - (a,b) SEMs, (c) Raman spectra, and (d) a TEM of as-grown CNTs by conventional thermal CVD $\left(x=0.65\right.$, annealing for 10 min with $\mathrm{H}_{2}(10 \mathrm{vol} \%) / \mathrm{CO}_{2}$ (3 vol\%)/Ar, CVD for 10 min with $0.5 \mathrm{vol} \% \mathrm{C}_{2} \mathrm{H}_{2}(0.5 \mathrm{vol} \%) / \mathrm{H}_{2}(10 \mathrm{vol} \%) / \mathrm{CO}_{2}(3 \mathrm{vol} \%) / \mathrm{Ar}$ at 800 or $\left.900{ }^{\circ} \mathrm{C}\right)$. The Raman spectra were taken at three different points for each sample. The peak at $300 \mathrm{~cm}^{-1}$ in (c) originates from the $\mathrm{SiO}_{2}$ layer on $\mathrm{Si}$ substrates. The white arrows in (d) indicate SWCNTs.

\subsection{Optimization of growth conditions}

From the results described above, short-time annealing of $\sim 10 \mathrm{~s}$ followed by CVD was found effective for SWCNT growth from flame synthesized nanopowders. Next, growth conditions were optimized to enhance yields and CNT crystallinity using the nanopowder with $x=0.65$, which showed the highest catalytic activity. 
Fig. 6 shows SEMs of CNTs grown under different $\mathrm{H}_{2}$ (3-20 vol\%) and $\mathrm{CO}_{2}(0-14$ vol\%) concentrations. The addition of $\mathrm{H}_{2}$ is intended to reduce the cobalt oxide, while addition of $\mathrm{CO}_{2}$ is intended to maintain the catalytic activity by etching carbonaceous byproducts by reaction of $\mathrm{C}+\mathrm{CO}_{2} \rightleftharpoons 2 \mathrm{CO}$ [12]. With small amounts of $\mathrm{H}_{2}$ (3 vol\%) (Fig. 6fi), CNTs grew well only when $\mathrm{CO}_{2}$ was added at 3 vol\% (Fig. 6g). CNTs grew better with higher $\mathrm{H}_{2}$ content (Fig. a-e) and/or longer annealing time (Fig. 6a,b), and CNTs grew well even without $\mathrm{CO}_{2}$ when annealed with 20 vol\% $\mathrm{H}_{2}$ for $10 \mathrm{~s}$ (Fig. 6a). Compared with conditions without $\mathrm{CO}_{2}$, addition of 3 vol\% $\mathrm{CO}_{2}$ improved both the quality (G/D ratio) and quantity of CNTs regardless of $\mathrm{H}_{2}$ content (Fig. 6b,d,g). Excess $\mathrm{CO}_{2}$ at $\geq 10$ vol\% resulted in fewer CNTs with lower G/D ratio, possibly due to the etching grown CNTs and/or inhibited reduction of the Co catalysts (Fig. 6e,h,i). Because the temperature fluctuates run by run, the repeatability of the CNT growth is examined at the standard CVD condition with 10 vol\% $\mathrm{H}_{2}$ and 3 vol\% $\mathrm{CO}_{2}$ (Fig. S3). The temperature fluctuation of $\leq 50 \mathrm{~K}$ caused some fluctuation in CNTs, but the $\mathrm{H}_{2}$ and $\mathrm{CO}_{2}$ concentrations showed more significant effects on the CNT yield and $I_{\mathrm{G}} / I_{\mathrm{D}}$ ratio.

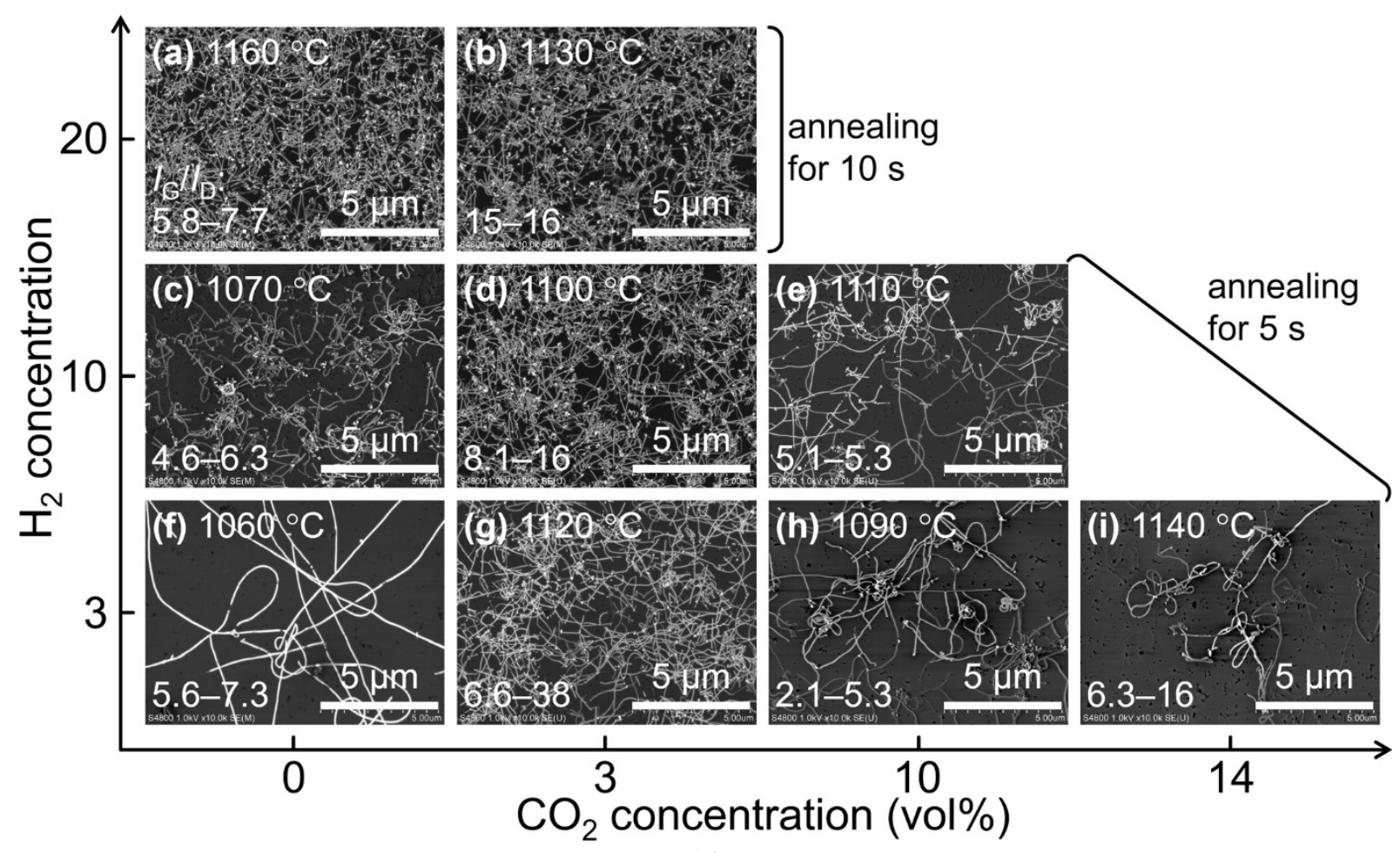


Fig. 6 - SEMs of CNTs grown with $\mathrm{H}_{2}$ and $\mathrm{CO}_{2}$ at various concentrations and $\sim 1100{ }^{\circ} \mathrm{C}(x=$ 0.65, annealing for 5-10 s with $\mathrm{H}_{2} / \mathrm{CO}_{2} / \mathrm{Ar}$, CVD for $10 \mathrm{~s}$ with $\left.\mathrm{C}_{2} \mathrm{H}_{2}(0.5 \mathrm{vol} \%) / \mathrm{H}_{2} / \mathrm{CO}_{2} / \mathrm{Ar}\right)$. $\mathrm{H}_{2}$ concentration (a,b) 20, (c-e) 10, and (f-i) 3 vol\% and $\mathrm{CO}_{2}$ concentration (a,c,f) 0, (b,d,g) 3, (e,h) 10, and (i) 14 vol\%. Actual temperature and G/D ratio of resulting CNTs are shown for each image. Raman spectra were taken at three different points for each sample.

Next, the annealing and growth temperatures were varied widely from 900 to $1230{ }^{\circ} \mathrm{C}$ under the standard gas conditions. Fig. 7 shows SEMs and the Raman spectra of grown CNTs. The SEMs show large amounts of CNTs covering the entire substrate at a low temperature of $900{ }^{\circ} \mathrm{C}$. Also, $100 \mu \mathrm{m}$ long CNT bundles grew from some parts of the nanopowders (Fig. S4). However, Raman spectra had $I_{\mathrm{G}} / I_{\mathrm{D}}$ ratios as low as 0.69 without any RBM peaks, showing the growth of large-diameter MWCNTs. As the temperature increases, CNTs grew with higher crystallinity. The split G-band peak with the presence of RBM peaks show the growth of SWCNTs at $\geq 1000{ }^{\circ} \mathrm{C}$. Especially, CNTs with high crystallinity $\left(I_{\mathrm{G}} / I_{\mathrm{D}}\right.$ ratio $>100$, e in Fig. $7 \mathrm{~g}$ ) were obtained at $1160{ }^{\circ} \mathrm{C}$. However the amount of CNTs decreased at higher temperatures. The catalysts coarsen faster at higher temperature [22], possibly resulting in fewer catalyst particles of suitable size and thus fewer CNTs. The RBM peaks appear at various wavenumbers between 120 and $200 \mathrm{~cm}^{-1}$ depending on the measurement positions, showing the broad diameter distribution of SWCNTs. 

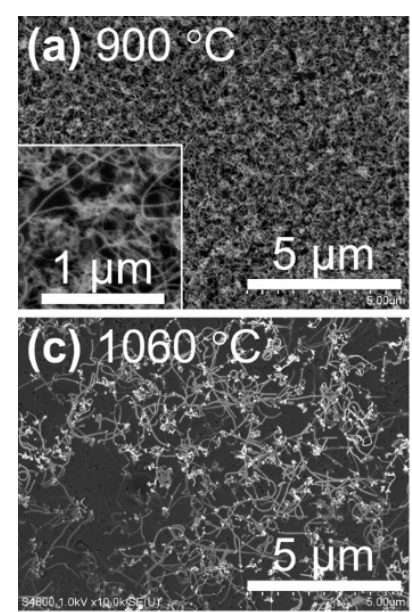

(e) $1160^{\circ} \mathrm{C}$

$5 \mu \mathrm{m}$

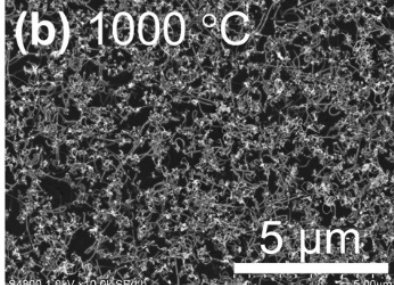

(d) $1110^{\circ} \mathrm{C}$

$5 \mathrm{~mm}$
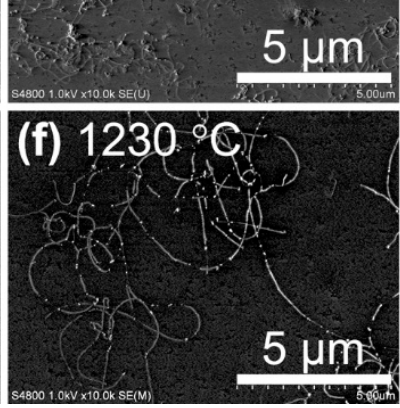

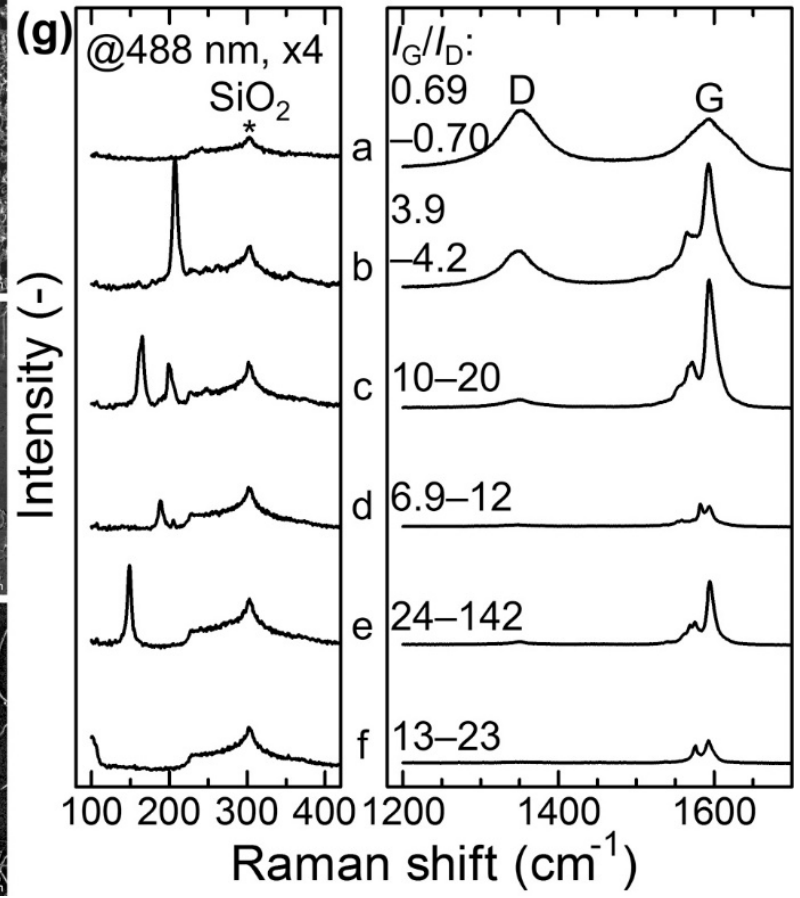

Fig. 7 - (a-f) SEMs and (g) Raman spectra of CNTs grown at different temperatures $(x=0.65$, annealing for $10 \mathrm{~s}$ with $\mathrm{H}_{2}(12.5 \mathrm{vol} \%) / \mathrm{CO}_{2}(3.8 \mathrm{vol} \%) / \mathrm{Ar}, \mathrm{CVD}$ for $10 \mathrm{~s}$ with $\mathrm{C}_{2} \mathrm{H}_{2}(0.5$ vol\%)/ $\left.\mathrm{H}_{2}(10 \mathrm{vol} \%) / \mathrm{CO}_{2}(3 \mathrm{vol} \%) / \mathrm{Ar}\right)$. Raman spectra were taken at 3 positions for each sample and one of them was shown in (g) with $I_{\mathrm{G}} / I_{\mathrm{D}}$ range.

Next, we investigated the effect of annealing time (from 0 to $60 \mathrm{~s}$ ) on the CNT growth (Fig. 8). Few CNTs were observed without annealing (Fig. 8a), showing that any Co must be reduced prior to exposure to $\mathrm{C}_{2} \mathrm{H}_{2}$ to grow CNTs efficiently. Whereas CNTs grew much better with the annealing for $\geq 2 \mathrm{~s}$, showing the Co reduction was rapid, require just a few seconds. SEMs and Raman spectra are similar with annealing times between 2-60 s. The segregated Co nanoparticles proved to be rather stable, for $\sim 1 \mathrm{~min}$ at $1100{ }^{\circ} \mathrm{C}$ and $\sim 10 \mathrm{~min}$ at $900{ }^{\circ} \mathrm{C}$ (Fig. 5b). 

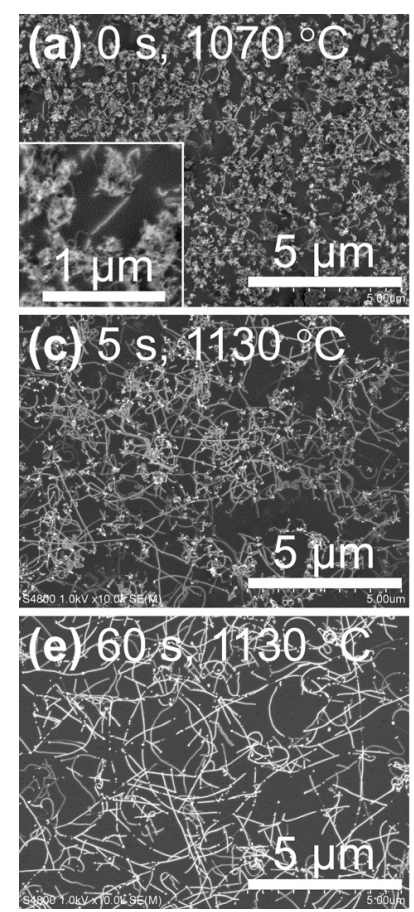
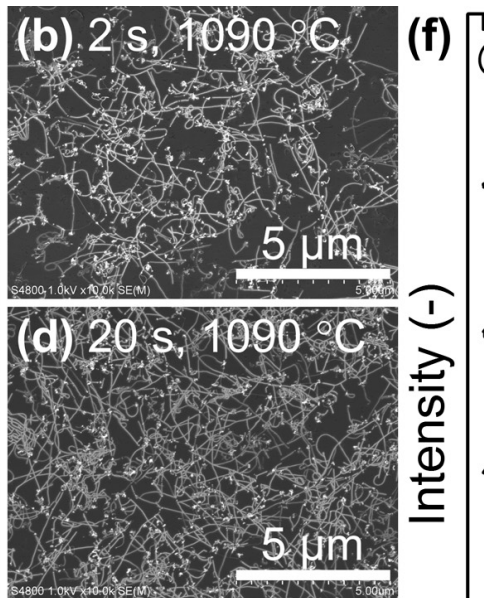

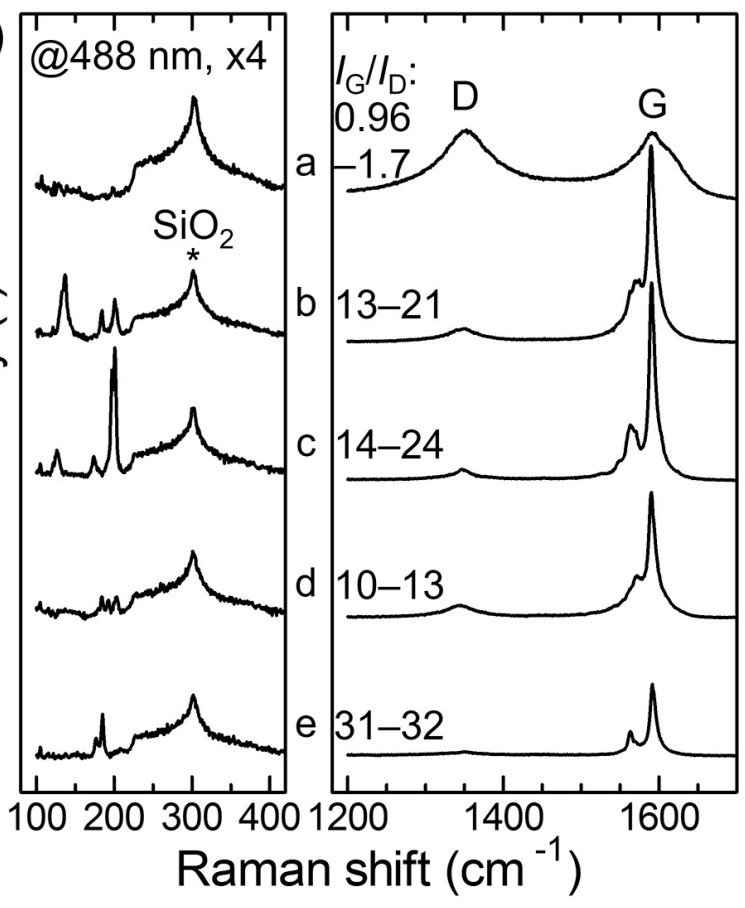

Fig. 8 - (a-e) SEMs and (f) Raman spectra of CNTs grown with different annealing time (shown as inset) $\left(x=0.65\right.$, annealing for $0-60 \mathrm{~s}$ with $\mathrm{H}_{2}(12.5 \mathrm{vol} \%) / \mathrm{CO}_{2}(3.8 \mathrm{vol} \%) / \mathrm{Ar}$ at $1100{ }^{\circ} \mathrm{C}$, CVD for $10 \mathrm{~s}$ with $\mathrm{C}_{2} \mathrm{H}_{2}(0.5 \mathrm{vol} \%) / \mathrm{H}_{2}(10 \mathrm{vol} \%) / \mathrm{CO}_{2}(3 \mathrm{vol} \%) / \mathrm{Ar}$ at $\left.1100{ }^{\circ} \mathrm{C}\right)$. Raman spectra were taken at 3 positions for each sample and one of them was shown in (f) with $I_{\mathrm{G}} / I_{\mathrm{D}}$ range.

Finally, we tried to grow CNTs with small diameters by using a nanopowder with a lower CoO content $(x=0.41)$ than the standard one $(x=0.65)$. Fig. 9 shows the SEMs and the Raman spectra of CNTs grown with different annealing time from 10 to $60 \mathrm{~s}$. CNTs did not grow with annealing for $10 \mathrm{~s}$, while CNTs grew well with annealing for $20 \mathrm{~s}$. The different time needed to activate nanopowders (2 s for $x=0.65$ vs $20 \mathrm{~s}$ for $x=0.41$ ) should have been caused by the different Co content (see Table 1) and the existence/absence of $\mathrm{CoO}$ in the as-synthesized nanopowders (Fig. S1). It has been known that only particles of specific sizes work well to grow CNTs and there is a gap in particle sizes between catalysts for SWCNTs and MWCNTs [31]. Annealing for 60 s resulted in very high G/D ratio, but fewer CNTs 
without RBM peaks, suggesting narrower window for CNT growth with $x=0.41$ than $x=$ 0.65. Therefore, the annealing condition has to be carefully optimized for different starting nanopowders to nucleate properly sized Co particles for small-diameter CNTs.
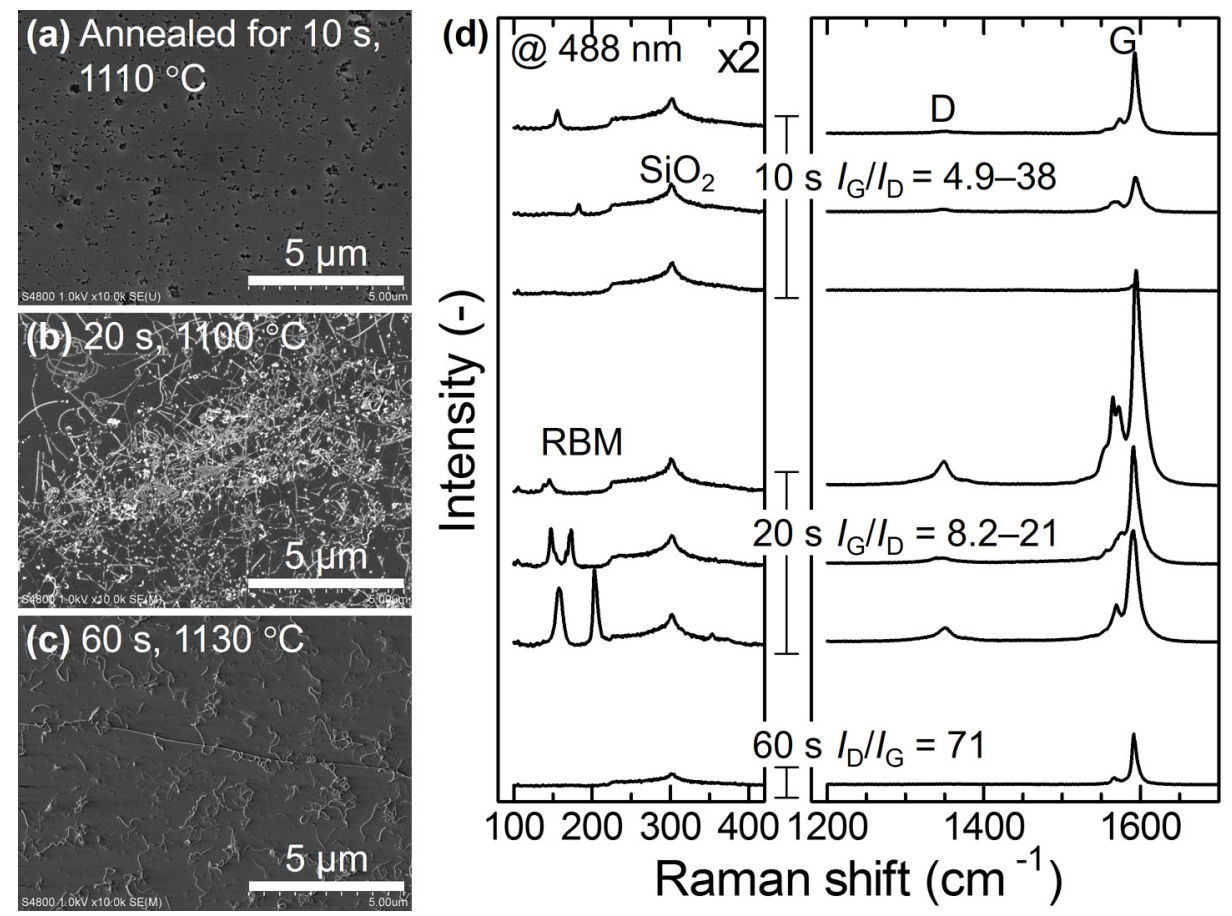

Fig. $9-(a-c)$ SEMs and (d) Raman spectra of CNTs grown from the nanopowder with $x=$ 0.41 at different annealing time (shown as inset) (annealing for 10-60 s with $\mathrm{H}_{2}$ (12.5 vol\%)/CO 2 (3.8 vol\%)/Ar, CVD for 10 s with $\mathrm{C}_{2} \mathrm{H}_{2}(0.5$ vol\% $) / \mathrm{H}_{2}(10 \mathrm{vol} \%) / \mathrm{CO}_{2}(3 \mathrm{vol} \%) / \mathrm{Ar}$ at $1100{ }^{\circ} \mathrm{C}$. Raman spectra were taken at 3 positions for each sample and one of them was shown in (d) with $I_{\mathrm{G}} / I_{\mathrm{D}}$ range. For the sample annealed for $60 \mathrm{~s}$, Raman peaks appeared at only one position.

\section{Conclusions}

Flame-synthesized, 20-nm-sized Co-Al-O nanopowders were examined as supported catalysts to grow small-diameter CNTs. The nanopowder with target Co contents $x \leq 0.35$ grew few CNTs whereas with $x=0.65$ CNTs grew quite well. The nanopowder with $x=0.65$ had the $\mathrm{CoAl}_{2} \mathrm{O}_{4}$ spinel with excess Co, which created Co catalyst particles on its surface. 
CNTs with small and moderate $I_{\mathrm{G}} / I_{\mathrm{D}}$ ratios grew at 800 and $900{ }^{\circ} \mathrm{C}$, respectively, by a conventional thermal CVD process with annealing and CVD in ten-minute time scale. Whereas highly crystalline CNTs including SWCNTs with $I_{\mathrm{G}} / I_{\mathrm{D}}$ ratio of $20-100$ grew from the nanopowder by annealing and CVD in ten-second time scale at $\geq 1000{ }^{\circ} \mathrm{C}$. Multiple Co particles with proper size for SWCNTs formed on single primary particles of the nanopowder in such a short time. $\mathrm{H}_{2}$ addition at 3-20 vol\% and $\mathrm{CO}_{2}$ addition at $3 \mathrm{vol} \%$ to the CVD gas promoted the growth of SWCNTs with high crystallinity. The Co-Al-O supported catalyst rapidly synthesized by flame, rapidly reduced and activated by $\mathrm{H}_{2}$, and growing CNTs from $\mathrm{C}_{2} \mathrm{H}_{2}$, all in ten-second time scale, is promising for practical, high-through-put production of small-diameter CNTs.

\section{Acknowledgements}

The authors thank Mr. Shinpei Enomoto at Kagami Memorial Research Institute for Materials Science and Technology, Waseda University for TEM observation. XRD and ICP-OES measurements were performed at Materials Characterization Central Laboratory, Waseda University. This work is financially supported by the Advanced Low Carbon Technology Research and Development Program (ALCA) by JST, Japan and JSPS KAKENHI Grant Numbers JP25107002 and JP16H06368, Japan. H.S. acknowledges the Leading Graduate Program in Science and Engineering, Waseda University from MEXT, Japan. The Laine group thanks NSF DMR for support through DMR grant 1105361. 


\section{References}

[1] Wu ZC, Chen ZH, Du X, Logan JM, Sippel J, Nikolou M, et al. Transparent, conductive carbon nanotube films. Science 2004;305(5688):1273-1276.

[2] Fukaya N, Kim DY, Kishimoto S, Noda S, Ohno Y. One-step sub-10 $\mu$ m patterning of carbon-nanotube thin films for transparent conductor applications. ACS Nano 2014;8(4): 3285-3293.

[3] Takenobu T, Takahashi T, Kanbara T, Tsukagoshi K, Aoyagi Y, Iwasa Y. High-performance transparent flexible transistors using carbon nanotube films. Appl Phys Lett 2006;88(3):033511.

[4] Cao Q, Kim HS, Pimparkar N, Kulkarni JP, Wang CJ, Shim M, et al. Medium-scale carbon nanotube thin-film integrated circuits on flexible plastic substrates. Nature 2008;454(7203):495-500.

[5] Sun DM, Timmermans MY, Kaskela A, Nasibulin AG, Kishimoto S, Mizutani T, et al. Mouldable all-carbon integrated cirucits. Nat Commun 2013;4:2302.

[6] Futaba DN, Hata K, Yamada T, Hiraoka T, Hayamizu Y, Kakudate Y, et al. Shape-engineerable and highly densely packed single-walled carbon nanotubes and their application as super-capacitor electrodes. Nat Mater 2006;5(12):987-94.

[7] Quintero R, Kim DY, Hasegawa K, Yamada Y, Yamada A, Noda S. Carbon nanotube 3D current collectors for lightweight, high performance and low cost supercapacitor electrodes. RSC Adv 2014;4(16):8230-7.

[8] Cui LF, Hu L, Choi JW, Cui Y. Light-weight free-standing carbon nanotube-silicon films for anodes of lithium ion batteries. ACS Nano 2010;4(7):3671-8.

[9] Lee SW, Gallant BM, Lee Y, Yoshida N, Kim DY, Yamada Y, et al. Self-standing positive electrodes of oxidized few-walled carbon nanotubes for light-weight and high-power lithium batteries. Energy Environ Sci 2012;5(1):5437-44. 
[10] Chen HM, Li F, Su G, Pan HY, He LL, Sun X, et al. Large-scale and low-cost synthesis of single-walled carbon nanotubes by the catalytic pyrolysis of hydrocarbons. Appl Phys Lett 1998;72(25):3282-3284.

[11] Saito T, Xu W-C, Ohshima S, Ago H, Yumura M, Iijima S. Supramolecular catalysts for the gas-phase synthesis of single-walled carbon nanotubes. J Phys Chem B 2006;110(12):5849-53.

[12] Nasibulin AG, Brown DP, Queipo P, Gonzalez D, Jiang H, Kauppinen EI. An essential role of $\mathrm{CO} 2$ and $\mathrm{H} 2 \mathrm{O}$ during single-walled $\mathrm{CNT}$ synthesis from carbon monoxide. Chemical Physics Letters 2006;417:179-184.

[13] Reynaud O, Nasibulin AG, Anisimov AS, Anoshkin IV, Jiang H, Kauppinen EI. Aerosol feeding of catalyst precursor for CNT synthesis and highly conductive and transparent film fabrication. Chem Eng J 2014;255:134-40.

[14] Fan S, Chapline MG, Franklin NR, Tombler TW, Cassell AM, Dai H. Self-oriented regular arrays of carbon nanotubes and their field emission properties. Science 1999;283(5401):512-514

[15] Murakami Y, Miyauchi Y, Chiashi S, Maruyama S. Direct synthesis of high-quality single-walled carbon nanotubes on silicon and quartz substrates. Chem Phys Lett 2003;377(1-2):49-54.

[16] Hata K, Futaba, D. N, Mizuno, K, Nanami, T, Yumura, M, Iijima, S. Water-Assisted Highly Efficient Synthesis of Impurity-Free Single-Walled Carbon Nanotubes. Science 2004;306:1362-4.

[17] Noda S, Hasegawa K, Sugime H, Kakehi K, Zhang Z, Maruyama S, et al. Millimeter-thick single-walled carbon nanotube forests: hidden role of catalyst support. Jpn J App Phys 2007;46(17):L399-401.

[18] Li WZ, Xie SS, Qian LX, Chang BH, Zou BS, Zhou WY, et al. Large-scale synthesis of 
aligned carbon nanotubes. Science 1996;274(5293):1701-1703.

[19] Flahaut E, Peigney A, Laurent C and Rousset A. Synthesis of single-walled carbon nanotube-Co-MgO composite powders and extraction of the nanotubes. J Mater Chem 2000;10:249-52.

[20] Kitiyanan B, Alvarez WE, Harwell JH, Resasco DE, Controlled production of single-wall carbon nanotubes by catalytic decomposition of $\mathrm{CO}$ on bimetallic Co-Mo catalysts. Chem Phys Lett 2000;317:497-503.

[21] Kim DY, Sugime H, Hasegawa K, Osawa T, Noda S. Submillimeter-long carbon nanotubes repeatedly grown on and separated from ceramic beads in a single fluidized bed reactor. Carbon 2011;49(6):1972-9.

[22] Hasegawa K and Noda S. Moderating carbon supply and suppressing Ostwald ripening of catalyst particles to produce 4.5-mm-tall single-walled carbon nanotube forests. 2011;49(13):4497-4504.

[23] Chen G, Davis RC, Kimura H, Sakurai S, Yumura M, Futaba DN, Hata K. The relationship between the growth rate and the lifetime in carbon nanotube synthesis. Nanoscale 2015;7:8873-8878.

[24] Hasegawa K and Noda S. Millimeter-Tall Single-Walled Carbon Nanotubes Rapidly Grown with and without Water. 2011;5(2):975-984.

[25] Amama PB, Pint CL, McJilton L, Kim SM, Stach EA, Murray PT, et al. Role of water in super growth of single-walled carbon nanotube carpets. Nano Lett 2009;9(1):44-50.

[26] Sugime H, Noda S. Millimeter-tall single-walled carbon nanotube forests grown from ethanol. Carbon 2010;48(8):2203-11.

[27] Azurdia J, Marchal J, and Laine RM, Synthesis and Characterization of Mixed-Metal Oxide Nanopowders Along the CoOx-Al2O3 Tie Line Using Liquid-Feed Flame Spray Pyrolysis J Am Ceram Soc 2006;89(9):2749-2756. 
[28] Sekiguchi K, Furuichi K, Shiratori Y, Noda S. One second growth of carbon nanotube arrays on a glass substrate by pulsed-current heating Carbon 2012;50:2110-8.

[29] Sugime H, Noda S. Cold-gas chemical vapor deposition to identify the key precursor for rapidly growing vertically-aligned single-wall and few-wall carbon nanotubes from pyrolyzed ethanol, Carbon 2012;50:2953-60.

[30] Jorio A, Saito R, Hafner JH, Lieber CM, Hunter M, McCure T, et al. Structural (n, m) determination of isolated single-wall carbon nanotubes by resonant Raman scattering. Phys Rev Lett 2001;86(6):1118-21.

[31] Kakehi K, Noda S, Maruyama S, Yamaguchi Y. Growth valley dividing single- and multi-walled carbon nanotubes: combinatorial study of nominal thickness of Co catalyst. Jpn J Appl Phys 2008;47(4):1961-1965. 

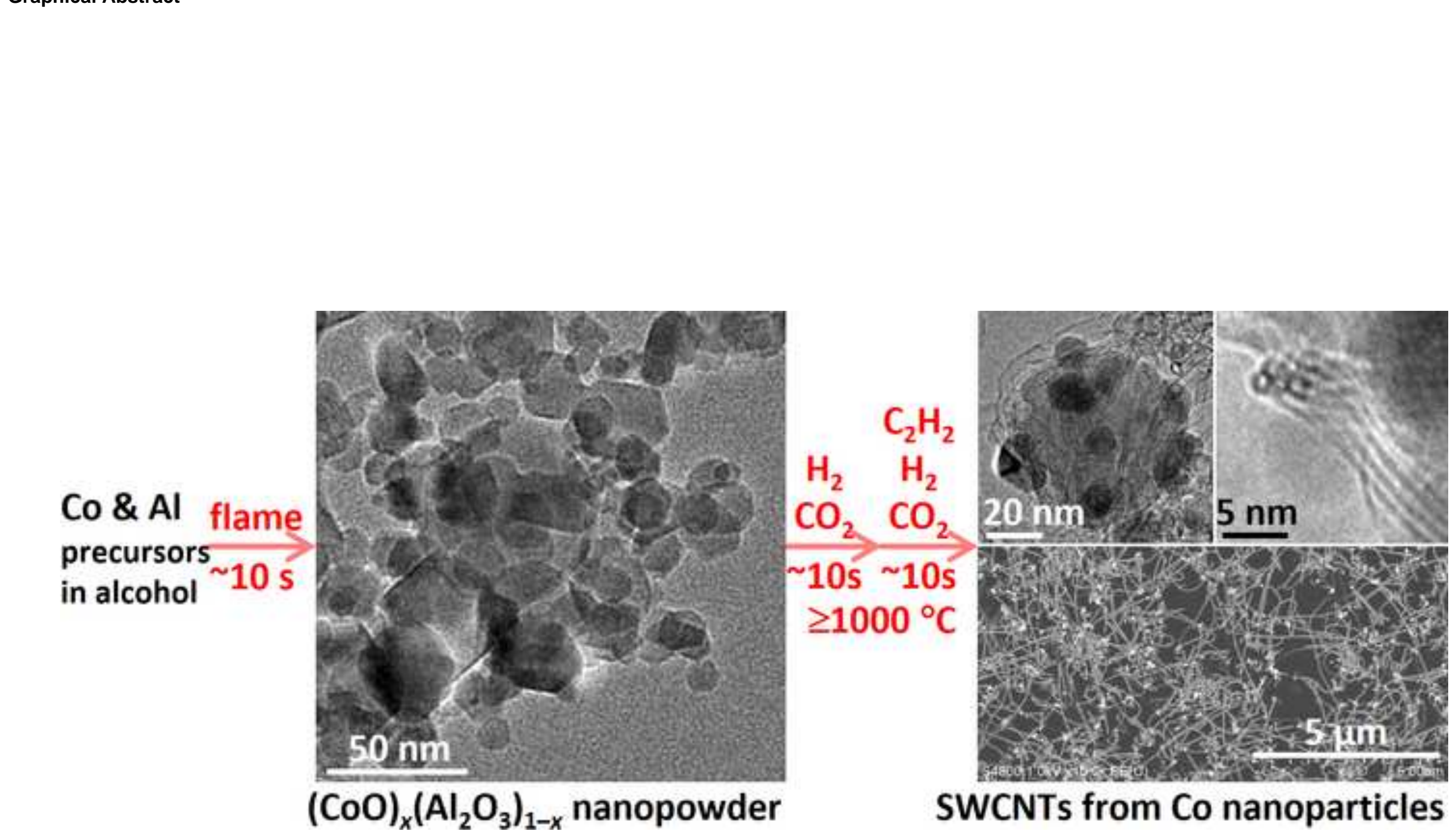

SWCNTs from Co nanoparticles 